\title{
Essential Design of the Great Pyramid Encoded in Hemiunu's Mastaba at Giza
}

\author{
Manu Seyfzadeh \\ Independent Researcher, Lake Forest, CA, USA \\ Email: manu@cheopspyramid.com
}

How to cite this paper: Seyfzadeh, M. (2018). Essential Design of the Great Pyramid Encoded in Hemiunu's Mastaba at Giza. Archaeological Discovery, 6, 162-172. https://doi.org/10.4236/ad.2018.62008

Received: March 23, 2018

Accepted: April 17, 2018

Published: April 20, 2018

Copyright $\odot 2018$ by author and Scientific Research Publishing Inc. This work is licensed under the Creative Commons Attribution International License (CC BY 4.0).

http://creativecommons.org/licenses/by/4.0/

c) (i) Open Access

\begin{abstract}
The architect of the "Great Pyramid"1 at Giza is believed to have been Khufu's half-nephew Hemiunu. While it is possible that Hemiunu conceived its design because he was both vizier and head of this king's works, there is no direct proof of it to date. Absent the unlikely discovery of unequivocal written evidence, whether he was involved may never be known with certainty. Here, I present evidence that Hemiunu himself was the likely brain behind the essential features of the Great Pyramid. The side length, height, the small indent into the core masonry on all four side centers, and even the factors five and eight which relate this pyramid with its smaller version at Meydum and which had significant theological meaning at the time are all embedded in the two original side lengths of Hemiunu's rectangular mastaba G4000 in the west cemetery. Furthermore, it appears that even the expanded sides of his mastaba enshrined key interior features of the Great Pyramid like the dimensions of the King Chamber and the shaft leading from it to the outside towards its presumed target in the northern night sky, the circumpolar star region centered around alpha-Draco Thuban. Unmistakable numerical clues embedded in the dimensions of Hemiunu's mastaba suggest that all this was done with intent, which thus lends compelling support to the notion that Hemiunu was the architect of the Great Pyramid attributed to Khufu.
\end{abstract}

\section{Keywords}

Great Pyramid, Khufu, Cheops, Hemiunu, Egypt, Giza, Seqed, Pyramid, Architecture, Archeoastronomy

\footnotetext{
${ }^{1}$ Ancient Egyptians of the Old Kingdom (see tomb of Idu in G1's east cemetery, for example) referred to Khafre's pyramid G2 as "Wr-Mr", i.e. "Great Pyramid". Khufu's pyramid G1 was called "Khufu Akhet”, i.e., Khufu's Horizon". Since nowadays the term Great Pyramid is commonly used to describe Khufu's pyramid however, I will adhere to this, albeit technically incorrect, convention in this paper. The terms "Great Pyramid" and "G1" are therefore used interchangeably throughout.
} 


\section{Introduction}

The Great Pyramid (a.k.a. Khufu's/Cheops' Pyramid, "Khufu Akhet", Giza-1, G1) stands on the Giza Plateau in Egypt and is commonly dated to the $26^{\text {th }}$ century B.C.E. (Figure 1; Lehner, 1997: p. 108). Its architect is unknown though circumstantial evidence suggests that it was Khufu's vizier Hemiunu entombed in mastaba G4000 to its west. The pyramid's unusual design has stimulated many theories about its origin. Some have questioned whether its concept is compatible with the knowledge and know-how of Old Kingdom Egyptians despite, albeit circumstantial, evidence which anchors its construction to Khufu's reign. In the absence of explicit written evidence which would unequivocally tie the idea behind its architectural design to this era, definitive proof will remain elusive, possibly forever. However, if the architect was in fact a contemporary of Khufu, he may have preserved the blueprints of his creation near the monument in a more durable medium than papyrus, i.e. stone, and recorded it in a more abstract architectural language than figures, i.e. numbers. This premise prompted me to investigate Hemiunu's mastaba for numerical clues which may identify him as the architect and definitively date the bulk of Gl's conception and construction to the $4^{\text {th }}$ Kingdom and thus more compellingly to Khufu's lifetime.

When fully cased, G1 was probably meant to be 440 royal Egyptian cubits (rc) wide at the base and 280rc high producing a side slope angle ("seqed") of 51/2 palms per each one cubit rise (Figure 1). A royal Egyptian cubit was sub-divided into seven palms ( $\mathrm{p}$ ) and each palm in turn was further subdivided into 4 fingers (f; $7 \times 4=28$ ). Its length in modern units has been subject to several investigations both inside and outside (Dash, 2012; Petrie \& Hawass, 1990: p. 28). The most accurate estimate of the original side length has yielded an average of 230.329 meters (m) within a possible error range of 230.135 - $230.493 \mathrm{~m}$ which means the length
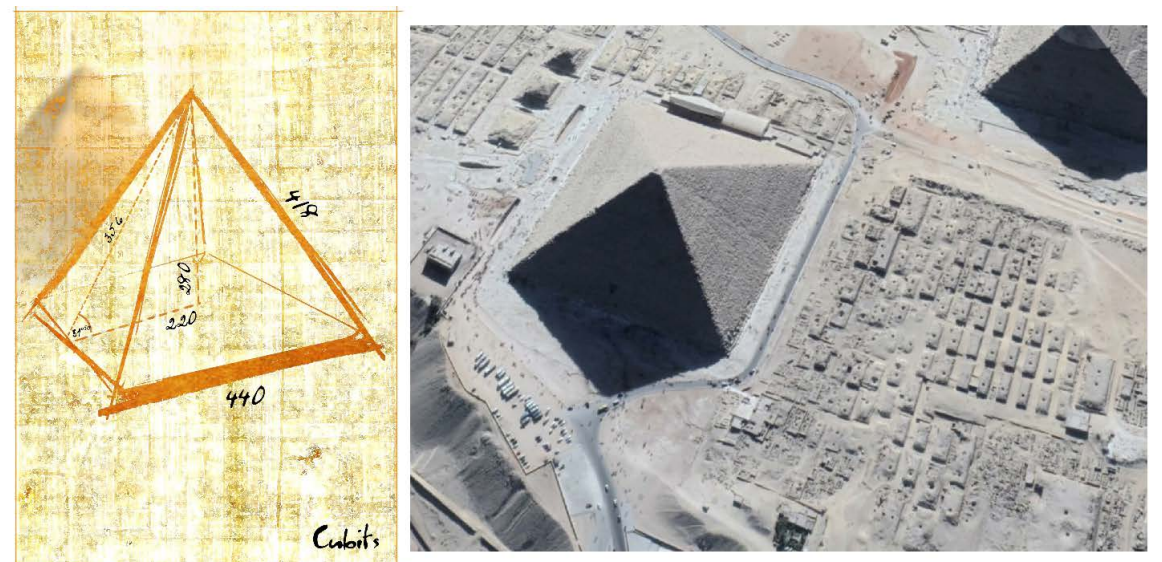

Figure 1. The dimensions of Khufu's pyramid given in royal cubits. The pyramid angle is $51^{\circ} 50^{\prime}$ or $5 \frac{1}{2}$ palms per cubit rise. On the right is an aerial view of Khufu's pyramid from the northwest showing the concavity which creates an eight-sided effect best seen here on the monument's west face. To the right of the pyramid is the west field. Hemiunu's mastaba G4000 is the larger rectangular structure close to the right edge of the image. Graphic by Anthony Adomaitis, Asturmas Studios. Satellite image by Google Earth. 
of the cubit used was $0.5235 \mathrm{~m}(230.329 \mathrm{~m} / 440 \mathrm{rc})$ within a possible variance range of $0.5230-0.5238 \mathrm{~m}$ (Dash, 2012: p.16). This royal cubit length is the basis for this paper's analysis.

The original smooth limestone casing of G1 was almost completely dismantled several centuries ago and only the core structure remains today. Its four triangular faces appear concave in certain lighting making the pyramid look eight-sided when the incident rays of the sun are parallel to the base such as is the case on the day of an equinox (Schoch \& McNally, 2005: pp. 219-220; Figure 1). This visual effect is caused by a small indent at the four side centers (Figure 2) amounting to $0.92 \mathrm{~m}$ or $1.76 \mathrm{rc}(\sim 1 \mathrm{rc}, 5$ palms, 1 finger), a value both theoretically predicted and measured (Bauval, 2016; Pochan, 1971: p. 234). Whether this feature was intended has been debated but the fact that all four sides are indented by the same amount makes a random event such as an earthquake less likely. A construction error caused by using an unsupported mason line has been proposed (Isler, 1983: p. 29), but this is also unlikely for the same reason. Therefore, the indent and concavity so created may have been an intentional architectural feature and may not be the result of earthquakes, the elements, or error.

Hemiunu was the son of Nefermaat and Itet and the grandson of Sneferu making Hemiunu Khufu's half-nephew. He carried several academic and priestly titles. He was vizier and head of the king's works (Junker, 1929: pp. 149-150, titles 3 and 20). He was also the chief of the Five of the House of Thoth. The Moon god Thoth was worshiped at Hermopolis ("Khemenu", "The Eight") alongside the Ogdoad, a group of four divine couples of frog and snake deities who, in the belief of its followers, constituted the primordial universe and created the world with a lotus flower from whose calyx the sun emerged (Wilkinson, 2003: pp. 77-78). The numbers five and eight also had potential

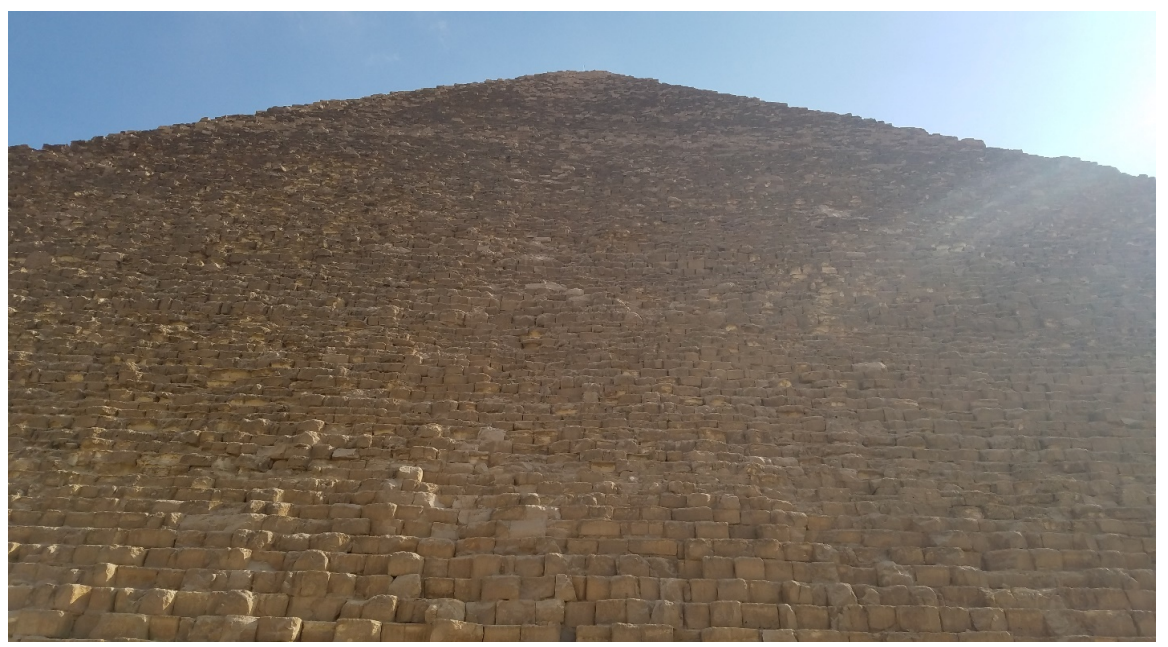

Figure 2. View of the west wall of Khufu's pyramid on a winter afternoon with the sun rays approximately parallel to the east and west base. The concavity is produced by an indentation which displaces the core from the original cased perimeter by a maximum of $0.92 \mathrm{~m}$ at the side centers, 220rc from the corners. Photo taken by the author in February 2017. 
astronomic significance because the planet Venus, the brightest object in the night sky after the Moon and likely worshiped as a form of Horus (Krauss 1997: p. 246), realigns with the night sky position of the star Sirius, the brightest star worshiped as Isis-Horus, after a period of eight sidereal years during which it undergoes five inferior conjunctions with Earth (Venus Transit 2012 You Tube video). During the time of an inferior conjunction, Venus appears first in the evening sky and then, a few days later, appears on the morning horizon, a celestial spectacle easily observable by the ancient Egyptians who also marked the heliacal rising of Sirius as the beginning of their natural year and the inundation of the Nile (Parker, 1950: p. 31).

These two numbers, five and eight, relate the dimensions of the Great Pyramid to the Meydum Pyramid believed to be cased immediately before G1 from an older structure built either by Sneferu or his predecessor Huni though it is not known whether the casing was ever completed (Lehner, 1997: pp. 97-100). The intended dimensions and seqed however can be plausibly reconstructed from the casing stone remnants at the base of the Meydum Pyramid. In a previous publication I argued that a conceptual model pyramid, 55rc at the base, $271 / 2 \mathrm{rc}$ at the half-base, and 35rc high was scaled up five times to produce the casing dimensions of the Meydum Pyramid and eight times to produce the dimensions of the Great Pyramid (Seyfzadeh, 2017). Both pyramids have the same shape, i.e. the same seqed of $5 \frac{1}{2}$ palms per cubit rise. In addition, the concavity-producing indent of G1's four sides at the bases by $1.76 \mathrm{rc}$ can be understood as the product of $8 \times 1 / 1000 \times 220 \mathrm{rc}$, G1's half-base length. This product would have had great symbolic meaning to the Hermopolitean theologian Hemiunu because the fraction $1 / 1000$ is a numerical representation of the Sun over the Lotus, i.e. "R3/Kha", and the number eight represented the Ogdoad (Seyfzadeh, 2017). Thus, four side-slope indents producing an eight-sided pyramid can be thought of as a megalithic symbol of the Hermopolitean cosmogony in which the "The Eight" are the petals of a lotus, represented by the pyramid, which bears the sun within. The precedence of a Lotus also seen as a pyramid-like symbol occurs in two versions of an oil tag attributed to $1^{\text {st }}$ Dynasty king Djer and the official Sw $\underline{\mathrm{d}}-\mathrm{k} 3$.

\section{Results}

The mastaba of Hemiunu is the second biggest structure in the west-field, the cemetery next to the Great Pyramid where high royal court officials from the Old Kingdom were entombed (Figure 3 ). The original dimensions at the base were reported by Junker to have been $47 \times 21.45 \mathrm{~m}$ (Junker, 1929: p. 132) which, using the average meter-to-rc conversion factor determined by Lehner and Goodman (Dash, 2012: p. 16), converts to 89.78rc (89rc, 5 palms, 2 fingers) by $40.97 \mathrm{rc}$ (40rc, 6 palms, 3 fingers) rounded to the next whole finger (Figure 4). The range of the conversion due to error as defined by Lehner and Goodman produces the following confidence interval for these two values: $89 \mathrm{rc} 5$ palms $-89 \mathrm{rc}$ 6 palms and 40rc 6 palms 3 fingers-41rc. The ratio between the two sides is nearly 2.2 to 1 , or $22 \mathrm{rc}$ per 10 . The mastaba was later enlarged to accommodate 


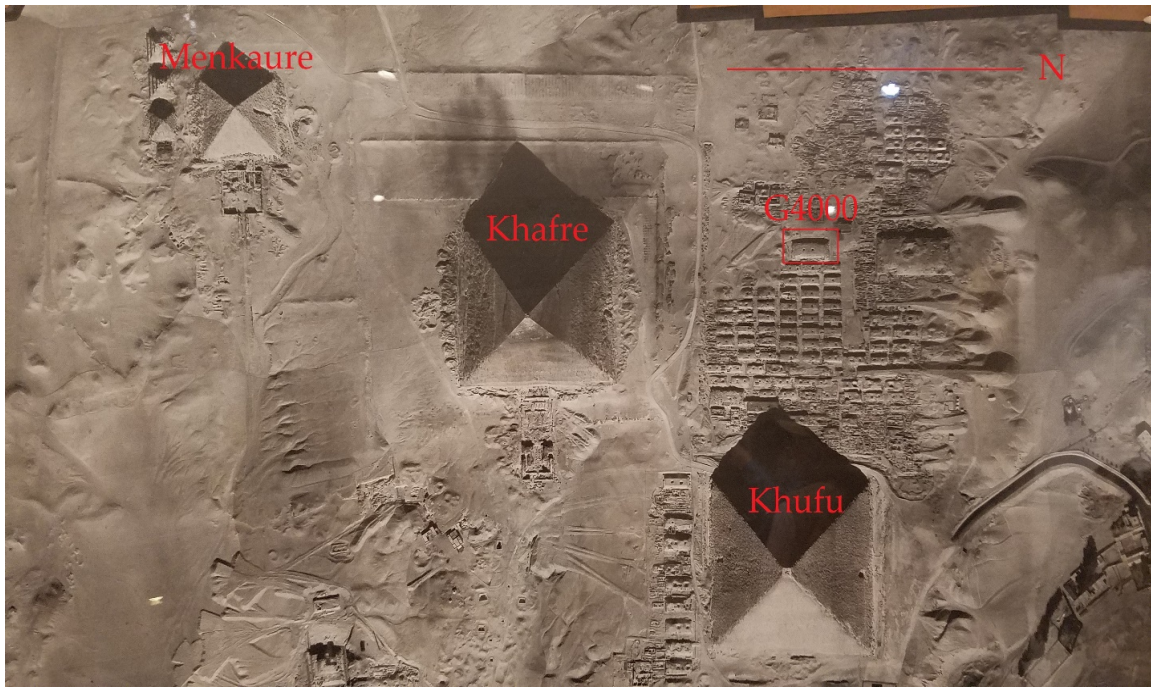

Figure 3. The Giza Pyramids, aerial view. Hemiunu's mastaba G4000 marked here with a red rectangle is west of Khufu's pyramid. Cairo Museum; photo taken by the author in 2017.

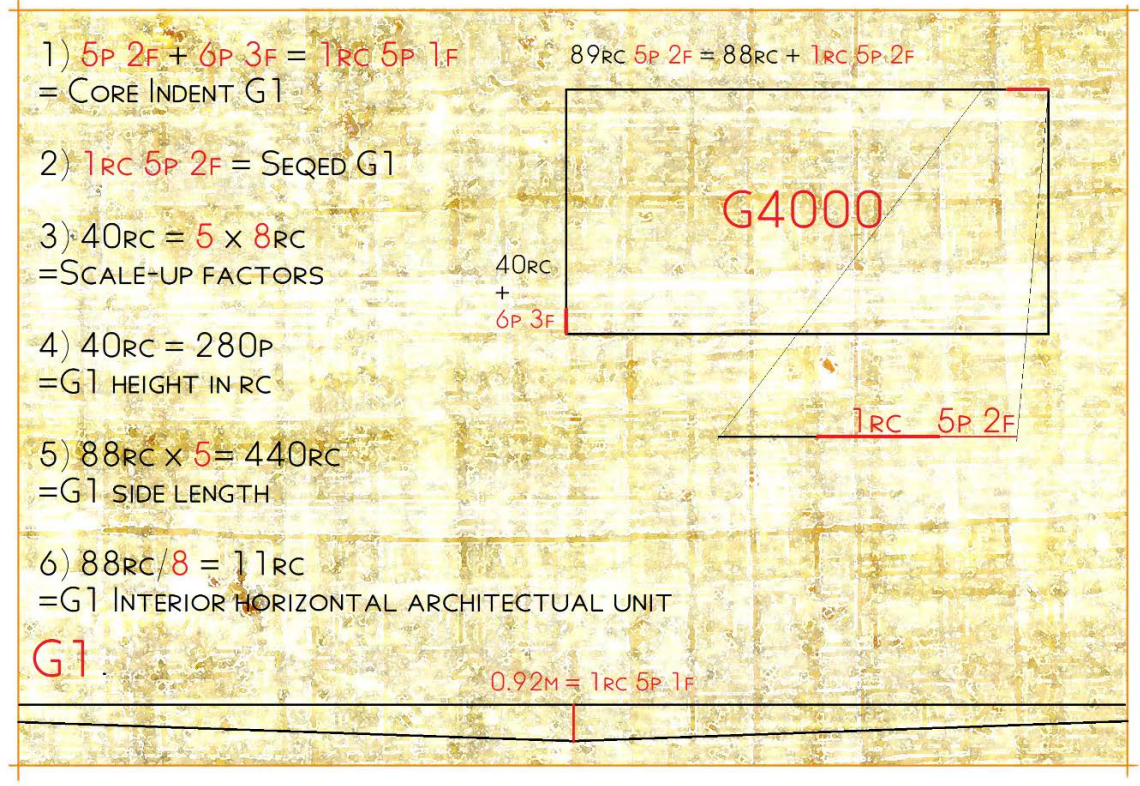

Figure 4. Illustration showing the original foot-print of Hemiunu's mastaba G4000 at the top right in the west-field of Khufu's pyramid (Giza-1, G1). The dimensions are given in royal cubits (rc), palms (p) and fingers (f). In red are shown the added amounts to the width and length which deviate them from recognizable whole numbers related to G1, i.e. 40 and 88 , respectively. Two possible deviations are shown for the length, $1 \mathrm{rc} 5 \mathrm{p} 2 \mathrm{f}$ added to $88 \mathrm{rc}$ or $5 \mathrm{p} 2 \mathrm{f}$ added to $89 \mathrm{rc}$ as shown in the magnified terminal segment. Each signifies an important exterior feature of G1, the seqed (feature 2) and one of two parts of the indent length (feature 1), respectively. The deviation from a whole number of $\mathrm{rc}$ for the width, i.e. $6 \mathrm{p} 3 \mathrm{f}$ combines with this part to sum up to the length of the indent shown at the bottom, 1rc 5p 1f. Only a short segment is shown for G1's base. The other encoded features are listed on the left. For illustration only not drawn to scale and other intervening structures not shown. 
additional features such as an enclosed offering room and false doors resulting in a wider $53.20 \mathrm{~m}(\sim 101 \mathrm{rc} 4 \mathrm{p} 1 \mathrm{f}) \times 26.77 \mathrm{~m}(\sim 51 \mathrm{rc} 1 \mathrm{p})$ foot-print and a nearly 2-to-1 length-to-width ratio (Junker, 1929: p. 135).

Thus, Hemiunu's original mastaba's design differed not only with respect to its size from the standard observed in the west-field, but also with respect to the proportions of the two sides, i.e. 2.2 versus $\sim 2 \frac{2}{3}$ (Junker, 1929: p. 16, see length/width ratios which compute based on values given in the Table part 1). Interestingly, the standard length of the west-field mastabas, $\sim 40 \mathrm{rc}$, appears to approximate the original width of Hemiunu's mastaba, with a difference of about one royal cubit ( 6 palms 3 fingers). This unusual deviation from a whole number value as well as the unusually disproportionate enlargement hint at a reason beside practical considerations why Hemiunu chose this design.

From this starting point, I asked if the $6 \mathrm{p} 3 \mathrm{f}$ deviation from the standard west-field mastaba width of 40rc could be a clue that the length also incorporated a small added amount of significance likewise causing it to deviate from an otherwise whole number dimension. The significance of 40rc is that it is the product of 5 and 8 , both numbers of great theological significance to Hemiunu as shown, and that the numerical value when converted to palms, 280, is identical with the Great Pyramid's height in royal cubits. If this was indeed the thought behind the choice of $40 \mathrm{rc}$, to which the short $6 \mathrm{p} 3 \mathrm{f}$ segment was added as a tip-off summing to the final width of Hemiunu's original mastaba design, then one should expect to discover the Great Pyramid's base and possibly its side-slope encoded in the length of Hemiunu's mastaba after subtracting a certain small amount of likewise significance in the design.

And this is in fact the case: $88 \mathrm{rc}$ times five is 440rc, G1's base. Of further significance is that $88 \mathrm{rc}$ divided by eight is $11 \mathrm{rc}$, the basic architectural unit of the horizontal dimension apparently used as a guide to construct the interior (Figure 4). The King Chamber, for example, is displaced south from the pyramid's central plane by $22 \mathrm{rc}, 2 \times 11 \mathrm{rc}$, and the rest of the interior design, the passages and shafts as they relate to the basic construction points, largely conform to this $11 \mathrm{rc}$ design unit as well (Gantenbrink, 1999). A near 22rc separation can also be observed in the distance between the north and south vertical shafts leading into G4000: 11.40 m (Junker, 1929: p. 141). After 88rc, the next greater whole number length is 89rc, which is also significant. One might be prompted to note an ambivalence in the proposed numerical design code at this point, i.e. whether attention to 88rc or 89rc was meant to be drawn, but both are significant and the apparent ambivalence suggests it. The factor 89/88 converts the Great Pyramid's perimeter of 1760rc ( $4 \times$ $440 \mathrm{rc}$ ) to $1780 \mathrm{rc}$ and $1 / 5$ of that number is equal to its side-slope length, 356rc (Figure 1). 89/88 also has astronomical significance (see Discussion).

The indents which produces the exterior concavity of the four core faces are maximal at their 220rc half-base points and displace the core face from the originally cased perimeter by 1.76 royal cubits (Figure 4 ). 1.76rc are $\sim 1 \mathrm{rc} 5 \mathrm{p} 1 \mathrm{f}$. The difference between $88 \mathrm{rc}$ and G4000's full original length of 89rc 5p 2f, i.e. 1 rc 5 palms 2 fingers, is one finger $(1.87 \mathrm{~cm} ; \sim 3 / 4$ inch) off this value (Figure 4$)$. The 
length of one finger is within the Lehner-Goodman confidence interval of the conversion from meters to royal cubits. But a better match yet can be obtained by simply adding the fractional cubit amounts in excess of the next near whole-number dimensions of the width (40rc) and length (89rc), i.e. $6 p 3 f+5 p$ $2 \mathrm{f}$, respectively, which equals $1 \mathrm{rc} 5 \mathrm{p}$ 1f. The fact that these fractional cubit amounts sum up to the length of the indent suggests that they are a clue planted to induce a look for additional information about the Great Pyramid in G4000's original dimensions. Of even greater significance yet is the fact that in the numerical value of the added segment to G4000's length past $88 \mathrm{rc}$, i.e. 1rc 5p $2 \mathrm{f}$, one can recognize G1's seqed: 51/2p per 1rc. Knowledge of the seqed and the base allows one to calculate the height of the Great Pyramid without the need to measure it: $440 \mathrm{rc} / 2 \times 7 \mathrm{p} / \mathrm{rc} \times 2 \mathrm{rc} / 11 \mathrm{p}=280 \mathrm{rc}$. This is powerful evidence that the connection between G4000 and G1 is not only real but was intended because the chance of an unintended random match with respect to all these features is low.

It is possible that the length of the indent was meant to represent the seqed and not the Hermopolitean cosmogony (i.e. 220rc $\times$ "Eight" $\times$ Re/Kh3 $=1 \mathrm{rc} 5 \mathrm{p}$ 1f), in which case the one finger difference, i.e. 1rc $5 p$ 1f versus $1 \mathrm{rc} 5 \mathrm{p} 2 \mathrm{f}$, is just an error of measurement. If in fact meant to be identical, the indent could have been the architect's way to score the pyramid at the base to reveal its height by simply revealing the seqed from which it easily computes. In either case, whether two distinct architectural features of G1 (indent and seqed) or just one (seqed) is represented at G4000, the occurrence is likely not random but intended due to its perfect numerical match.

\section{Discussion}

The original design of Hemiunu's mastaba features two peculiarities, first, unusual deviations from the otherwise round numbers 40rc, which was a standard length in other mastabas nearby, and 89rc, and second, the unusual length-to-width ratio of 2.2 likewise deviating from the west-field's standard. Both appear to be planted clues that its dimensions related to G1's architectural design. If these two features were intentionally incorporated into G4000's dimensions as a hint to reveal the entire numerical design concept of the Great Pyramid's exterior core and cased features and even the basic architectural unit used to design its interior, they constitute the architect's intent-revealing numerical signature on his design. Therefore, whoever designed this mastaba most likely also designed the Great Pyramid and the most likely candidate to have designed the mastaba is Hemiunu himself. It is not known who expanded Hemiunu's mastaba from the original dimensions. It is possible that it was done after his death explaining why his numerical design code was inadvertently buried with the expansion of the perimeter to build a votive space for Hemiunu's relatives. It is also possible that Hemiunu himself wanted to hide or protect his design code by sealing it within a new layer of blocks just like he effectively sealed the four indents into the Great Pyramid's core with a smooth, presumably non-indented, layer of Tura limestone casing. The motivation behind this effort to conceal the design may have been the 
changing theological focus from that of Memphis (Ptah) and Hermopolis (Ogdoad, Thoth) to that of Heliopolis (Re) during Khufu's reign (Seyfzadeh, 2017).

But the possibility remains that the expansion was also guided by the idea to encode yet more design features of the Great Pyramid, for example from its interior. Applying the same method used to decode the original mastaba, the differences of the expanded mastaba's length and width to 100rc and 50rc, respectively, sum up to $2 \mathrm{rc} 5 \mathrm{p} 1 \mathrm{f}(1 \mathrm{rc} 4 \mathrm{p} 1 \mathrm{f}+1 \mathrm{rc} 1 \mathrm{p}) .100 \mathrm{rc}$ and $50 \mathrm{rc}$ are five times the dimensions of the pyramid's King Chamber, 20rc $\times 10 \mathrm{rc}$ (Petrie \& Hawass, 1990: pp. 27-28) but what is the significance of the summed deviations from these whole numbers? The answer lies in the unusually accurate orientation of the Great Pyramid to the cardinal directions. Its north-south axis is almost perfectly aligned to the celestial north pole varying only slightly by less than 4 arc-minutes from true north (Dash, 2012: p. 16). Using the same reasoning as above that the fractional amounts might add up to the numerical components of an angle of importance, one obtains a $12^{1 / 4} \mathrm{p}(1 \mathrm{rc}+5 \mathrm{p}+1 \mathrm{f})$ run per $1 \mathrm{rc}$ rise, which translates into an angle of $29.74^{\circ}$ (inverse tangent $7 \mathrm{p} / 12^{1 / 4} \mathrm{p}$ ). This angle is nearly midway between alpha-Draco Thuban's minimum and maximum meridional transit altitude angles as seen from Cairo/Memphis in the mid- $26^{\text {th }}$ century B.C.E. (e.g. 2550 B.C.E.; Figure 5), $28.75^{\circ}$ and $31.43^{\circ}$, respectively (obtained using Stelarium version 0.14 .3 ). In that era, Thuban was a close marker of the rotational center of the "imperishable stars", i.e. the celestial north pole to where Egyptian kings yearned to ascend after death. If the numerical value $2 \mathrm{rc} 5 \mathrm{p}$ if was in fact meant to encode the seqed $7 \mathrm{p} / 12 \frac{1}{4} \mathrm{p}$, it was a very close approximation to this star's average altitude around 2550 B.C.E, circa $30.09^{\circ}$.

$29.74^{\circ}$ is also within circa 2 degrees of the average incline angle of the north shaft leading from the King Chamber to the Great Pyramid's exterior $\left(31.20^{\circ}\right.$ $32.60^{\circ}$; Gantenbrink, 1999; 30.72 - 32.07 ${ }^{\circ}$ Petrie \& Hawass, 1990: p. 29). Whether or not this and the other three shafts (King Chamber south, Queen chamber north and south) were built as symbolic passage ways to certain stars of importance to the ancient Egyptians has been debated between Bauval \& Gilbert (1994, chapter 9; Figure 20; Appendix I) and Gantenbrink (1999)². The findings presented here suggest that Thuban's celestial position in the $26^{\text {th }}$ century B.C.E. mattered to Hemiunu, but in isolation do not prove a link between Thuban and the north shaft emerging from the King Chamber nor favor either researcher's theory over the other's.

However, there is another clue that Hemiunu designed the shaft to aim for the zone around Thuban as proposed by Bauval and Gilbert. The King Chamber's north shaft begins in its north wall above the $51^{\text {st }}$ course, i.e. within the $52^{\text {nd }}$

\footnotetext{
${ }^{2}$ Bauval has argued that the shafts were made to point to Sirius and Al-Nitak in the south and Kochab and Thuban in the north with the best match occurring in the mid- $25^{\text {th }}$ century B.C.E. using manually calculated corrections to star positions due to precession and proper motion. Gantenbrink has argued that the shafts' orientations are a result of geometric rules imposed by the shifting south of the King Chamber and the desire to have them exit at the same course. Stelarium (version 0.14.3) gives $31.43^{\circ}$ and $32.00^{\circ}$ for Thuban's maximum altitudes in 2550 B.C.E. and 2450 B.C.E., respectively.
} 


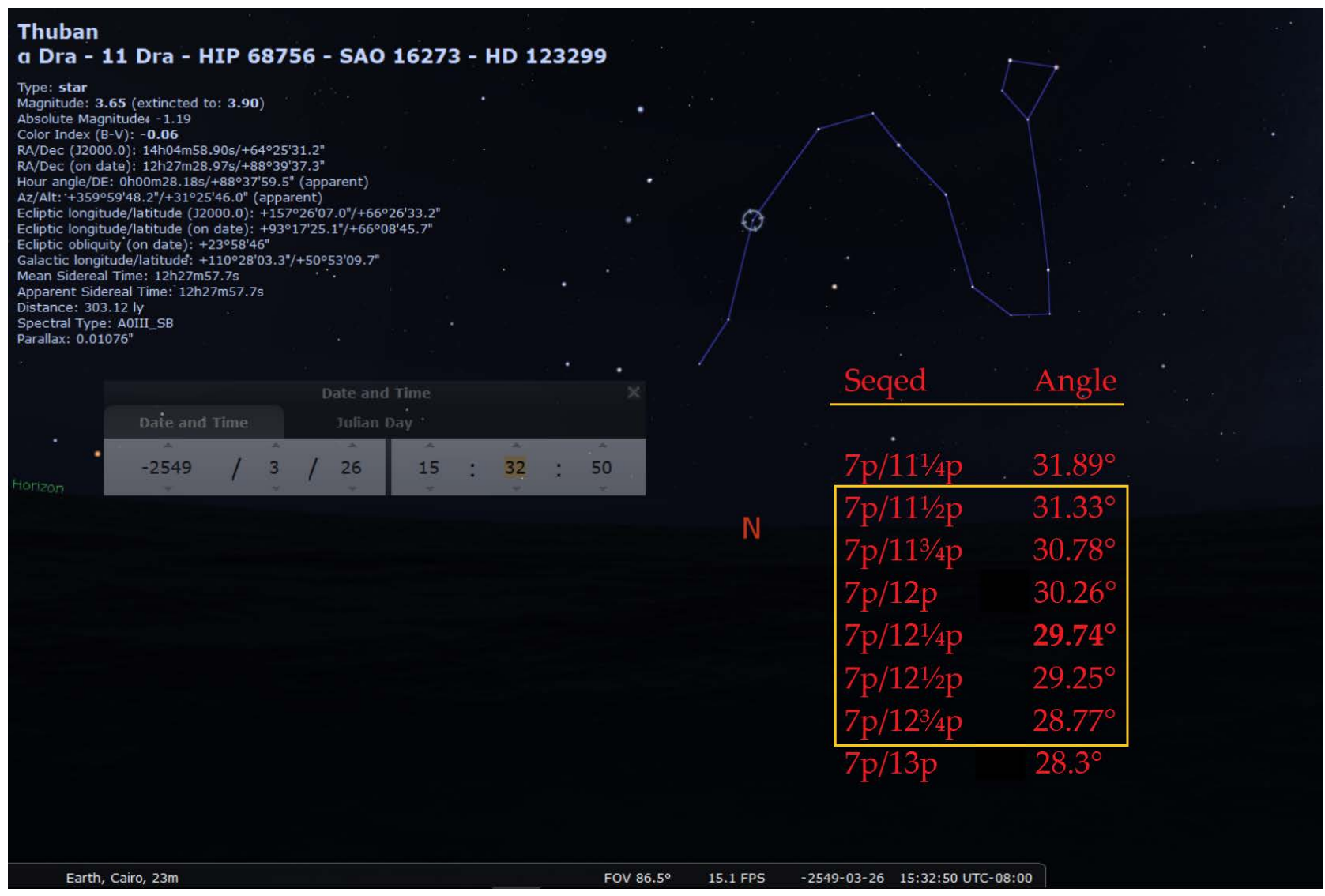

Figure 5. Thuban, alpha-Draconis shown as it would have appeared from the Cairo area in 2550 B.C.E. (Julian year-2549) as part of the constellation Draco in the northern night sky. The circumpolar stars, which the ancient Egyptians believed to be imperishable spirits, are always visible throughout the year but the center of rotation around the celestial north pole changes gradually due to precession. In 2550 B.C.E., Thuban was close to the rotational center. The table on the right shows the range of possible seqeds and corresponding angles which would have encompassed the star's 2550 B.C.E. altitude range boxed in gold, its average being $30.09^{\circ}$ above the horizon. Angles are calculated by taking the inverse tangent of the seqed ratios. Shown in bold red is the seqed and corresponding angle encoded in the expanded dimensions of G4000. Illustration made using Stellarium.

course, of the Great Pyramid and currently open-ends on its north face above the $101^{\text {st }}$ course, presumably within the $102^{\text {nd }}$ course when it was fully cased. This shaft has previously been suspected to represent one, if not the, ultimate purpose of the pyramid: A symbolic passage for Khufu's spirit resurrected in the King Chamber to ascend towards the center of the imperishable stars (i.e. Hawass citing Badawy; Petrie \& Hawass, 1990: p. 101). And in fact, the start and end of this passage, numerically marked by fractional amounts over 51 and 101, respectively, are represented by the expanded lengths of Hemiunu's mastaba: $51 \mathrm{rc} 1 \mathrm{p}$ and $101 \mathrm{rc} 4 \mathrm{p} 1 \mathrm{f}$. The fact that this passage is thus context-appropriately encoded together with the dimensions of the King Chamber and the Great Pyramid's orientation towards the celestial north pole within the expanded length and width of Hemiunu's mastaba is an unmistakable clue of Hemiunu's intent to aim the King Chamber's north shaft at the imperishable star zone centered around Thuban.

That astronomy also played a significant role elsewhere in the Great Pyramid's 
design is suggested by the $89 / 88$ factor encoded in the original length of Hemiunu's mastaba. Observing synodic months (circa 29.53 days after which the Moon returns to a certain shape), predicting solar eclipses (Saros Cycle) or recurrent Moon shapes on certain calendar dates (Metonic Cycle) were all complicated by the difficulty in visually pin-pointing New Moon (Parker, 1950: pp. 9-10). By contrast, a sidereal lunar month, which is the time it takes the Moon to return to a fixed position in the night sky, could have been more accurately observed by the ancient Egyptians to last circa $271 \frac{1}{2}$ days using any prominent asterism near the ecliptic (Seyfzadeh, 2017). However, this observed period differs slightly from the true period, 27.32 days and the difference becomes more pronounced over longer time spans. Thus, neither a Saros cycle (6585 days, 223 synodic months, 241 sidereal months) or a Metonic cycle (6940 days, 235 synodic months, 254 sidereal months) could have been directly predicted using a $27 \frac{1}{2}$-day count to represent a month.

Indirectly however, any whole number " $Y$ " of such months can be converted to a corresponding whole number of synodic months " $Z$ " by the following formula: $\mathrm{Y} \times 27^{1 / 2}$ days $\times 89 / 88=\mathrm{Z} \times 29.53$ days $\times 28^{1 / 2} / 28$. For example, $241 \times 27^{1 / 2}$ days $\times 89 / 88=223 \times 29.53$ days $\times 28^{1 / 2} / 28$ for the Saros Cycle and $254 \times 271 / 2$ days $\times 89 / 88=235 \times 29.53$ days $\times 281 \frac{1}{2} / 28$ for the Metonic cycle. Thus, the significance of the $89 / 88$ factor to Hemiunu, if he recognized it, may have been that it related a more accurately observable sidereal lunar period to solar eclipses which were of arguably great theological significance to the ancient Egyptians. One such total eclipse over Memphis during the summer solstice may have occurred over Memphis during the early reign of Khufu (Seyfzadeh, unpublished observation). Hints of prior attempts to relate the sidereal and synodic lunar periods can be observed in the dimensions of the core layers E1 and E2 of the Meydum period and the colonnade at Djoser's Pyramid (Seyfzadeh, 2017). The observable lunar sidereal period of $27^{1} / 2$ days, when converted to cubits, was also a possible theme incorporated into the exterior dimensions of several Egyptian pyramids including the Great Pyramid (Seyfzadeh, 2017).

\section{Conclusion}

In summary, all essential exterior and interior design features of the Great Pyramid at Giza can be found in the original and expanded dimensions of Hemiunu's mastaba in its west-field once the unusual deviations from whole number values are noted. Their presence is compelling evidence that they were added intentionally as clues to reveal the essential design themes used to plan this pyramid. While there is a remote possibility that Hemiunu incorporated G1's architectural design into his own mastaba without having conceived it, the much more likely possibility is that he wanted to record his design for posterity in such a way that it could be retrieved. G4000 thus became Hemiunu's blue-print for G1 firmly anchoring its conception to the $4^{\text {th }}$ Dynasty and the reign of Khufu. Likely, therefore, the Great Pyramid indeed belonged to Khufu.

The theory presented here makes the testable prediction that visible man-made 
marks may be found on either G4000's original small-block masonry or on its post-expansion large-block façade to designate the fractional cubits amount proposed here and demarcate them from the overall dimension.

\section{Acknowledgements}

I would like to thank Alan Green for helpful discussions and for confirming the length of the indent when we visited the site in 2017.

\section{References}

Bauval, J.-P. (2016). The Concavity of the Great Pyramid: A Design Feature? Did the Designer Know the Meter Unit? https://www.academia.edu/27553148/THE_CONCAVITY_OF_THE_GREAT_PYRA MID_a_design_feature_Did_the_designer_know_the_Meter_Unit

Bauval, R., \& Gilbert, A. (1994). The Orion Mystery: Unlocking the Secrets of the Pyramids. New York: Three Rivers Press.

Dash, G. (2012). New Angles on the Great Pyramid. AERAGRAM, 13, 10-19.

Gantenbrink, R. (1999). Ascertaining and Evaluating Relevant Structural Points Using the Cheops Pyramid as an Example. http://www.cheops.org/

Isler, M. (1983). Concerning the Concave Faces on the Great Pyramid. Journal of the American Research Center in Egypt, 20, 27-32. https://doi.org/10.2307/40000899

Junker, H. (1929). Giza I. Die Mastabas der IV. Dynastie auf dem Westfriedhof. Hölder-Wien und Leipzig: Pichler-Tempsky A.-G.

Krauss, R. (1997). Astronomische Konzepte und Jenseitsvorstellungen in den Pyramidentexten. Wiesbaden: Harrassowitz Verlag.

Lehner, M. (1997). The Complete Pyramids. Solving the Ancient Mysteries. London: Thames \& Hudson Ltd.

Parker, R. (1950). The Calendars of Ancient Egypt. The Oriental Institute of the University of Chicago, Studies in Ancient Oriental Civilizations, No. 26. Chicago: The University of Chicago Press.

Petrie, W. M. F., \& Hawass, Z. (1990, Original: 1883). The Pyramids and Temples of Gizeh. London: Histories \& Mysteries of Man.

Pochan, A. (1971). L'Enigme'de la Grande Pyramide. Paris: Robert Laffont.

Schoch, R. M., \& McNally, R. A. (2005). Pyramid Quest: Secrets of the Great Pyramid and the Dawn of Civilization. New York: Penguin Group.

Seyfzadeh, M. (2017). The Mysterious Pyramid on Elephantine Island: Possible Origin of the Pyramid Code. Archeological Discovery, 5, 187-223.

https://doi.org/10.4236/ad.2017.54012

Venus Transit (2012). You Tube Video. https://youtu.be/hUhLod8pDhU

Wilkinson, R. H. (2003). The Complete Gods and Goddesses of Ancient Egypt. New York: Thames \& Hudson. 